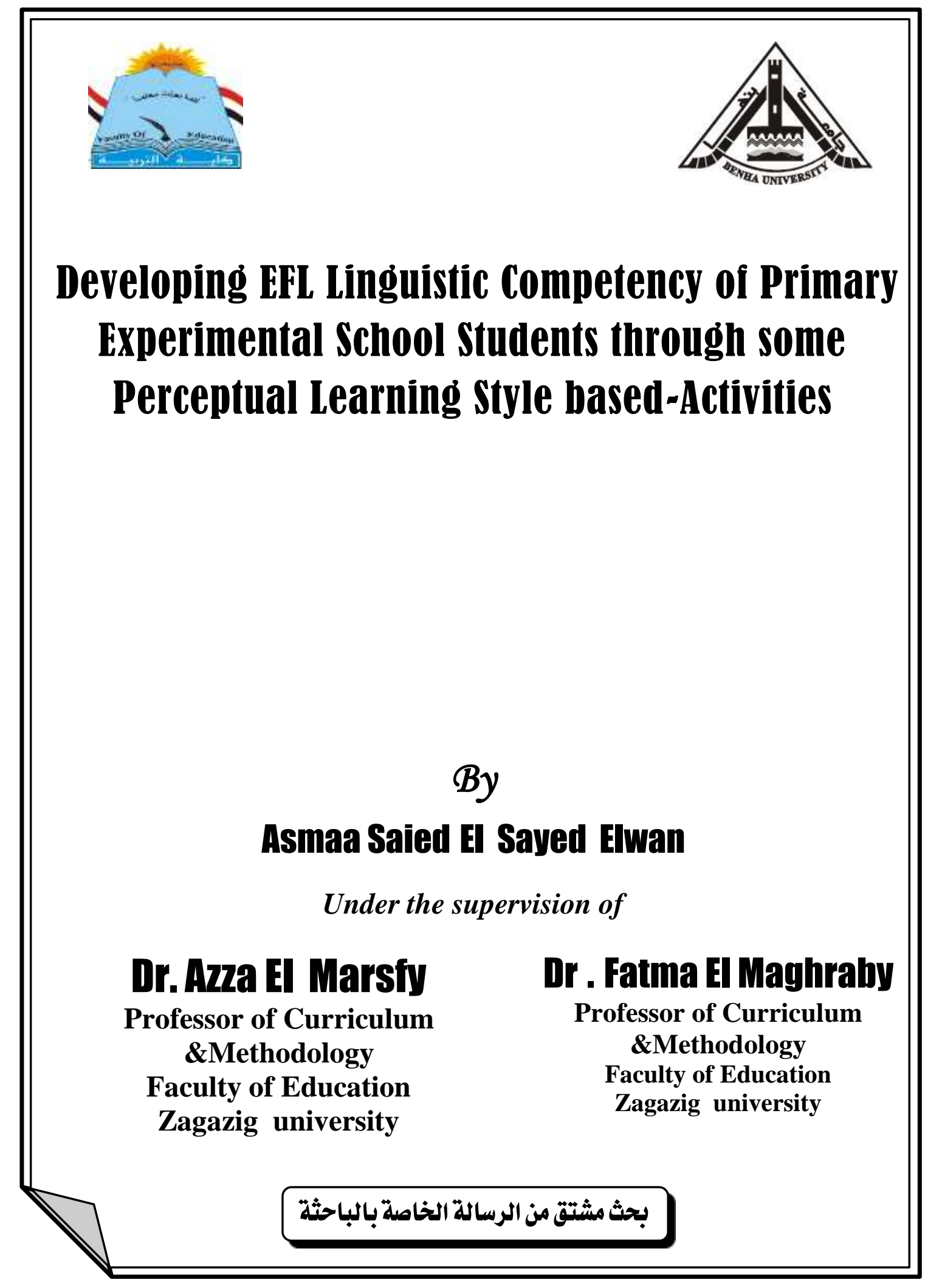




\section{Developing EFL Linguistic Competency of Primary Experimental school Students through some Perceptual Learning Style based-Activities}

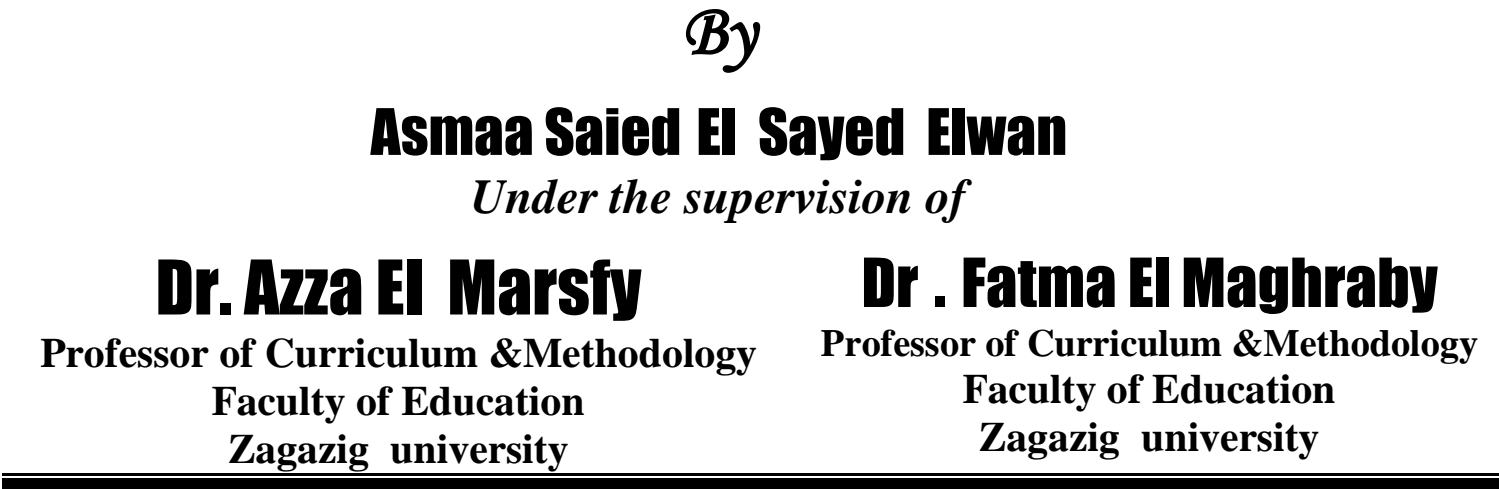

\section{Chapter one}

\section{Introduction}

Language is related to humans, created, spoken, performed and evaluated by humans. It is the primary source of communication to share thoughts and feelings. English language is the primary language of several countries. It is an official language in several African and European countries. It is learned around the world in schools by children as a foreign language. It is common while travelling, doing business, or in any other contexts. About twenty percent of the world's population speaks English as a first or a second language. It is also the dominant language in the field of Education and science.

Linguistic competency is one of the main components of communicative competency. It is a system of linguistic knowledge possessed by native speakers that is in contrast to the concept of linguistic performance. It is also the way in which the language system is used in communication. The concept was first introduced by Chomsky as a part of his generative grammar, but it had also been adopted and 
developed by other linguists. According to Chomsky, competency is the ideal language system for speakers to produce and understand an infinite number of sentences in their language and to distinguish grammatical sentences from ungrammatical sentences. This is unaffected by grammatically irrelevant conditions such as speech errors, Byram \&Stevens (2001).

Linguistic competency is a term used by experts and anthropologists to describe how language is defined among a community of speakers. Linguistic skills involved in choosing and creating messages are conveyed via the addressed words which are relatively simple; like activating a one-word message to request preferred items. Sometimes the addressed linguistic skills are complex, such as; making a complete sentence with a word from core words to retell a story for a reading group. Linguistic skills are important for all students, who use multimodel communication, Cook (2003).

Linguistic competency is also one of the most important and influential theoretical paradigms. The difference between competency and performance was used by the linguist Noam Chomsky (1980). He considered it a universal, inherited and organized ability to acquire the mother tongue. A limited system of linguistic principles and abstract rules combined with a certain learning process.

According to Chomsky, linguistic competency allows each normal person to acquire the mother tongue. It includes the ability to create and understand an unlimited variety of a novel, and a grammatically correct sentence. Hence linguistic competency underlies creative rule based language use and language learning, Bagaric \& deijunivoc (2007). 
Goode \& Jones (2004) defined linguistic competency as the capacity of an organization and persons to communicate effectively and convey information in a manner that is easily understood by different persons.

Many researches focused on the lack of the linguistic competency of the students. Goode \& Bronheim (2006) examined the evidence base for cultural and linguistic competency in health care. They conducted a structured research to identify the outcomes of linguistic competency about health care. Koda (2005) showed that the lack of linguistic skills unfamiliarity of asking questions, investigating, interpreting and reporting results are great problems.

Samaranayake (2016) investigated oral competency of ESL learners in Srilanklan rural school context. The study investigated the current trends and practices of teaching oral English in rural medium schools in Srilank .It also investigated the relationship between competency and the current pedagogical perspectives of second language acquisition. Cambridge Key English for school tests was used to set the structured speaking test. The results revealed that a majority of rural school students demonstrated a low proficiency level in oral communication in English. The study recommended promoting changes in teaching English as a foreign language. The previous related studies concentrated on the same problem of EFL competency, which is the main problem of the current study.

Marisol (2008) investigated linguistic competence in English language as a general indicator of communicative competence. The participants were 1838 undergraduate from five major institutes of 
higher education in Mexico. A test and a questionnaire were administered. The results showed that English language teaching and learning, not only in puplic schools, but also in private ones; requires dealing with the concept of linguistic competency. So, the notion of linguistic competency is an important contribution to understanding language and linguistics. It means realizing using grammar, syntax, and vocabulary of a language.

Learning styles deals with each student with his or her preferred way in acquiring information. This fact will be discussed in the following lines.One of the studies which suggested the idea of the current study is Napaporn (2016). It was recommended that the teachers should make students aware of their learning style preferences and different approaches to learning. The study aimed to study cognitive learning styles of EFL students and the relationship between English background knowledge and language learning style. The study instrument was a questionnaire which was used to collect data to identify cognitive styles. The participants were 210 undergraduate students enrolled in a fundamental English course at Bangkok University. The results revealed the importance of determining the students' cognitive learning style. It was found that students who had a high English background liked to apply a lot of language learning styles, but the students' language learning styles were at the moderate level.

A learning style is biologically and developmentally determined set of personal characteristics that makes identical instruction effective for some students and ineffective for others, Dunn \& Dunn (1992). An individual takes the responsibility for histher own learning 
characteristics. It is now well acknowledged that some experts attempt to understand learning through the primary senses involved (I. e. Visual, auditory, or tactile), so learning styles are related to learning how to learn and the manner in which information is processed and analyzed.

According to Dunn (1993), and Graboski and Jonassen (2003) learning styles are ways learners use to process, internalize and retain new information. From different perspectives learning styles have been identified in more than one domain. It has been defined in terms of cognitive, physiological and affective styles and lastly in terms of intelligences. Bedford (2004) mentioned that matching or mismatching students' learning styles with instructional techniques affects learning significantly.

More recently, Hall and Moseley (2005), who investigated learning-style models, identified 71 models of learning styles published between 1902 and 2002. They analyzed in depth 13 learning-style models and to group 50 of them based on the extent to which the developers of the models and instruments believe that learning styles don't change. The question of whether learning styles are fixed or can change is a subject of debate.

Dunn and Dunn (1993) stated that learning style is more than the process of remembering by seeing, hearing, reading or writing. LSs are also more than one's way to process either analytically, holistically or sequentially. In addition, it is more than one's preference in responding to environmental features or the type of input. It was asserted that these elements are only a part of the learning style construction. 
Dunn and Dunn (1993) investigated learning styles as the way in which each learner begins to concentrate process and retain information. That interaction occurs differently for everyone. Cassidy (2004) introduced an overview of theories and measures of models. The study aimed at clarifying common areas of ambiguity and in particular issues surrounding measurements and appropriate instruments. Transformational grammar was a theory of a new kind, concerning the subject matter on which there had scarcely been asked before becoming the central areas of research. The methodology was fundamentally changed. All of this brought about a great increase in our understanding of the area.

Myers and Myers (1990) indicated that people use their mental abilities to deal with people, ideas and things. They concluded that learning styles are the way that people use to perceive and encompass the process of becoming aware of things, concepts and people, so it is the way that they use to judge and refer to the conclusion of what they perceive.

Reid (1998) identified learning styles in terms of contrasting learning strategies. She maintained that learning styles are internal characteristics which learners use unconsciously to absorb process and retain new information.

Reid (1998) defined learning styles as the internal characteristics unconsciously used by learners to comprehend information. She stated that each individual has more than one learning style type, some are weak and some are strong. According to this model, learners are divided into six types with respect to their preferences. 
The researcher stressed three types of perceptual learning style based activities; visual perception activities, auditory perception activities and kinesthetic perception activities. Visual perception activities can help a child make sense of the information that his eyes send to the brain. There is an overlap between the different categories of visual perception and some activities that can be used to boost more than one skill. Visual learners are more comfortable seeing a film than listening to a lecture. Auditory perception refers to the ability of the brain to interpret and create an impression of sound. Good auditory skills enable children to distinguish sounds, rhythms and sources and words.

Auditory learners are socially oriented; they prefer to learn by interacting with others. They like playing by ear and making up songs, but they don't read well. They memorize well because of their ability to remember sounds. An auditory learner depends on hearing and speaking as a main way of learning. He must be able to hear what is being said to understand it, but he may have a difficulty with instructions.

Kinesthetic learning is a term that was frequently used by educators on the assumption that it is automatically a good thing for those who experience the daily reality of teaching classes. Kinesthetic learning can be stressful and exhausting to manage, when it is used for its own sake, rather than for a clearly identified educational purpose. It is also questionable to what extent it aids or leads to new learning.

Kinesthetic learning is done with positively bodily movements and with a variety of fine-tuned physical skills in the service of learning. It is associated with a "hand on doing" approach in which children are physically involved in the process of learning through many things such 
as manipulating objects, movement gym, dance, drama, mime, craft activities or making models. Kinesthetic learning activities are usually active and enjoyable.

Many studies discussed the importance of learning styles. Rossile (1989) discussed perceptual preferences and their relationship to language learning strategies in adult students of English as a second language. The study aimed at stating contributions of what will prove useful in the process of developing teaching methodologies.

Renou (2008) investigated a study of perceptual learning styles and achievement in a university level of foreign language course. The study proved the effectiveness of perceptual learning styles on raising the achievement level. The participants were eighty two English speaking students, whose native language is Spanish. The study used a learning style questionnaire which is considered as a self-report instrument. The results of the study did not show any statistically significant advantages to preferring one learning style over another (i.e. Visual, auditory, tactile or a combination). This might be good news for the foreign language student, because having a particular learning-style preference in this study did not provide an advantage or disadvantage for the learning outcome.

Kratzig \& Arbuthnott (2006) investigated perceptual learning styles and learning proficiency. The Participants were sixty five university students (54 females, 11males) with means of 23125 years old. They used a self-assessment tool and the Barsh learning style inventory questionnaire developed by Reid (1984). The study proved the positive relationship between the perceptual learning styles of the students and 
their learning proficiency, which supports the objectives of the current study.

Reza and Sarab (2013) investigated the perceptual learning style relationship with their gender, age, and discipline and self-proficiency level. Participants were 138 graduate students at the Shahid Behesti University, Tebran, Iran. The results revealed that the students preferred kinesthetic learning styles and disfavored group learning, gender and age. The second result was that perceptual learning style emerged in the study was an important element to consider during constructing a theoretical model of an acquired language. The fact that students from different disciplines tended to perform well within differential learning styles and could greatly help material producers develop suitable learning materials.

Ringo (2014) examined learning style preferences and activities for practicing the use of English tenses in Estonian basic school. Another study which proved the relationship between learning styles and critical thinking is Lowy's study (2013) who demonstrated that with regards to preferred learning styles. The critical thinking aptitudes of the subjects in the study were comparable to students in other health profession programs while the evaluative skills were strong.

From the previous studies, it is noticed that research efforts in second language instruction has over the past ten years changed from an emphasis on the role of the teacher to that of the learner. Learning style is a student centered approach. Researchers have explored the relationship between learning styles and second language acquisition. The importance of the current study resides in that a student learns best 
by seeing the value and importance of the information presented in the classroom. If the students are not interested in the material presented, they will not learn it. In order to achieve the ultimate goal of students learning, the classroom environment should be as stimulating and interactive as possible. The previously mentioned studies concentrated on the relationship between perceptual learning style and language acquisition, but rare researches investigated the relationship between perceptual learning style based-activities and linguistic competency.

\section{2-The context of the problem}

The researcher conducted a pilot study in the academic year 2017/2018 to investigate if sixth grade primary school pupils had problems with EFL acquisition skills. So she designed a test in order to measure their linguistic competency. The results of the pilot study revealed that students have problems in linguistic competency because their scores were $45 \%$. They would not be able to put words together to form phrases not to use grammar, syntax and vocabulary acquisition. Their expressive ability in speaking and writing were quite poor.

A number of studies such as: Lehman (2006), Lee (2008), Rmklassen (2010), Williams (2010), Hassan (2004), Castro and Pick (2005) confirmed that students lack the ability to use language efficiently. Al Alami (2014) investigated promoting communicative competence within EFL contexts in the United Arab Emirates. The problem was found in the area of teaching English as a foreign language. The participants were undergraduate students. The study recommended developing EFL linguistic and communicative competency. 
Hence, the researcher suggested some perceptual learning style based activities, i.e. visual, auditory, kinesthetic or tactile to handle the previous stated problems. Many researchers asserted on the effectiveness of perceptual learning style preferences of students on their achievement and their linguistic competency.

\section{3-Statement of the problem:}

The problem of the study could be stated as follows:

Sixth grade primary school pupils are poor in critical thinking skills and the competency of linguistic skills, so the problem could be tackled through the following question:

"What is the impact of using some perceptual learning style- based activities on linguistic competency skills of the sixth grade primary school pupils"?

\section{The following sub questions were also tackled:}

1- What are the skills of linguistic competency targeted for the sixth grade primary school pupils?

2- How far do these students perform these linguistic skills?

3- How can sixth grade pupils be distributed according to their LSs?

4- How can these perceptual learning styles based-activities be designed?

\section{4-Purpose of the study:}

\section{The present study aimed to:}

1- improve linguistic competency of the sixth grade primary school pupils. 
2- examine the impact of using visual learning based -activities on linguistic competency of the sixth grade primary school pupils.

3- examine the impact of using auditory learning style basedactivities on linguistic competency of the sixth grade primary school pupils.

4- examine the impact of using kinesthetic learning style basedactivities on linguistic competency skills of the sixth grade primary school pupils.

\section{5-Significance of the study:}

It was hoped that this study would be significant to:

1- Pupils: It might be useful for them to overcome the difficulties which usually face them in using the grammar, syntax, and vocabulary and to be able to analyze, and interpret information

2- Teachers: It might help them develop activities that address various types of learners. It might help them manage their classroom environment, so it increases the proportion of the teachers' self-efficacy.

\section{6-Study delimitations}

\section{The study would be delimited to:}

1- 54 primary school pupils divided into three experimental groups and a control group, because children unlike adults, have clear learning styles, and it would be fun for them to learn by using different activities which make the learning environment more attractive and the process of the acquisition of EFL more exciting. 
Students at this stage of educational system are more responsive for using the activities.

2- Three kinds of learning activities (visual, auditory, and kinesthetic), because these kinds match the primary stage pupils preferred way of learning.

3- Place and time delimitations:

- At El Swedi experimental school in Diarb Negm and the time of the application of the current study was in the first semester of the academic year 2017/2018.

\section{7-Instruments of the study:}

\section{It would be prepared by the researcher;}

1- A list of perceptual learning styles based - activities

2- A list of linguistic skills

3- A linguistic competency test.

4- A perceptual learning style preference questionnaire (PLSQ).

\section{8-Study Design:}

The study adopted both descriptive analytic and quasiexperimental designs. The first is used to identify linguistic competency, and perceptual learning style activities to develop both of them. Secondly, the quasi-experimental design which is used to state the impact of the three kinds of learning styles activities on linguistic competency using one control group and three experimental groups were randomly assigned to four classes. The treatment groups were taught through visual, auditory and kinesthetic learning style based activities, whereas the control group was taught through the traditional method. 


\section{9-Hypotheses of the study:}

1- There would be a statistically significant difference between the means of the scores of the (first, second and third) experimental groups on their pre- post linguistic competency tests, in favor of their scores in the post tests.

2- There would be a statistically significant difference between the mean scores the (first, second and third) experimental groups and the control group on the linguistic competency test, in favor of the experimental groups.

\subsection{0-Study Procedures:}

This study would be conducted using these procedures;

1- Surveying the literature and the previous studies concerning learning styles, linguistic competency.

2- Surveying the content of the English language course of Sixth grade primary school students to determine grammar, vocabulary, and syntax.

3- Designing the visual, auditory and kinesthetic learning activities.

4- Designing the perceptual learning style preference questionnaire, linguistic competency test.

5- Choosing a random sample of sixth grade primary school pupils as an experimental group.

6- Dividing students into a control group and an experimental group.

7- Teaching vocabulary, syntax, grammar and to the experimental group using visual, auditory and kinesthetic learning activities by the researcher using the designed activities 
8- Administering the pre-tests of linguistic skills and on the control group and the three experimental groups.

9- Administering the post-tests of linguistic skills and on both the experimental and the control group.

10- Comparing the results of all groups.

11- Treating data statistically for extracting results using the SPSS.

12- Discussing the results of the study.

13- Drawing conclusions, providing recommendations and suggestions for further research.

\section{Results of the study:}

1- The three experimental surpassed the control group in the post administration of the EFL linguistic competency test.

2- The auditory, visual and kinesthetic groups did better in the post administration of the linguistic competency test.

3- The visual, auditory and kinesthetic learning style based activities developed the level of linguistic competency of the three experimental groups as compared to the control group.

\subsection{2-Terms of the study:}

\section{1-Perceptual learning style:}

Reid (1998) defined it as the internal characteristics unconsciously used by learners to comprehend information. She states that each individual has more than one learning style type. Dunn \&Dunn (1993) defined it as the way used by students to concentrate on, process, internalize, and remember new difficult information. 
Operationally, learning style can be defined as the preferred way which the student uses to deal with information, comprehend its meaning; hence he will be able to recall it easily.

\section{2-visual learning style:}

To Vincent \& Ross (2001), Visual learners have clear imagination, learn by seeing images. They find verbal instructions difficult, they prefer the visual sense, and learn best by reading and watching.

Operationally, visual learning can be defined as the kind of learning in which information is associated with images. This learning style requires each individual to have more than one learning style.

\section{3-auditory learning style:}

Vincent \& Ross (2001) defined auditory learners as persons who enjoy talking and listening and have difficulty with written instruction. They must listen to, understand and learn best by listening to an explanation

Operationally, auditory learning can be defined as a learning through which a learner learns through listening. Auditory learners are people who retain information that is heard, and remember it using words, they easily process verbal information.

\section{4-kinesthetic learning style:}

Bagel et al (2004) defined kinesthetic learning style as an instructional technique which engages students by putting them in 
motion and sometimes even requiring real exertion, raising heart rates that tag during lecture.

Operationally, kinesthetic learning could be defined as a learning style in which learning takes place by the students carrying out physical activities, rather than listening to a lecture or watching a demonstration.

\section{5-linguistic competency:}

Phillips \& Tan (2004) defined it as the system of rules that governs an individual's tacit understanding of what is acceptable and what is not in the language. Castillo (2004) defined linguistic competency as it could only be verified in speaking. It is to be verified, described, and interpreted. On the second hand, speaking involves two factors; the agent of the activity and the thing made.

Operationally, linguistic competency can be defined as mastering the combination of sounds, syntax, and semantics known as the grammar of language. Students should be able to utilize the grammar of their spoken language to generate an unlimited amount of statements. 


\subsection{3-References:}

1- Abidin , M., Rezaee , A., Abdullah, H., \& Singh, K. (2011). Learning styles and overall academic achievement in a specific educational system. International Journal of Humanities and Social Science, 131, (10), 143-152.

2- Al Alami, S. E. (2014). Promoting Communicative Competence within EFL Contexts: A UAE Case Study. Journal of Language Teaching \& Research, 5 (6).

3- Bagarić, V., \& Djigunović, J. M. (2007). Defining communicative competence. Metodika, 8 (1), 94-103

4- Begel A, Garcia D, \& Wolfman S, (2004) " kinesthetic learning in the classroom. ACM. SIECSE Bulletin, 36 (1), 138-184.

5- Byram, M., Nichols, A., \& Stevens, D. (Eds.). (2001). Developing intercultural competence in practice (Vol. 1). Multilingual Matters.

6- Chomsky, N. ( 1986). Knowledge of language. New York, A critique of behaviorist.

7- Cook, G. (2003). Applied linguistics. Oxford University Press.

8- Dunn, R., Dunn, K., Price, G. (1981). Learning style inventory. New York Lawerence, KS: Price systems.

9- Dunn, R., \& Dunn, K. (1993). Teaching secondary students through their individual learning styles: Practical approaches for grades 7-12 prentice hall.

10- Felder, R., Felder, G., \& Diettz, E. (2002). The effects of personality types in engineering Education, 9 (1), 3-17. 
11- Goode, T. D., Dunne, M. C., \& Bronheim, S. (2006). The evidence base for cultural and linguistic competency in health care. New York, NY: Commonwealth Fund.

12- Hirari, A. (1999).The relationship between listening and reading rates of Japanese EFL learners. Journal of Social Sciences, 83, 367-348

13- Kang,J.Y.(2005).Written narratives as an index of L2 competence in Korean EFL learners. Journal of second language writing, 14(4), 259-279.

14- Krätzig, G. P., \& Arbuthnott, K. D. (2006). Perceptual learning style and learning proficiency: A test of the hypothesis. Journal of educational psychology, 98(1), 238.

15- Lasagabaster, D. (2008). Foreign language competence in content and language integrated courses. The Open Applied Linguistics Journal, 1 (1).

16- Lowy, N. (2013). Learning styles, critical thinking aptitudes, and immersion learning in physician assistant students.

17- Mohamed, R., \& Anani, S. (2011). Perceptual learning style preferences among Iranian graduate students. Doctoral Dissertation. University of Tehran, Iran.

18- Mota, M. (2008). Linguistic Competence in English and Exposure Factors. Online Submission.

19- Napaporn, S. (2016). Cognitive learning styles of EFL students. The Behavioral and Brain Sciences, 8, 15-23.

20- Nejmaoui, N. (2019). Improving EFL Learners' Critical Thinking Skills in Argumentative Writing. English Language Teaching, 12(1), 98-109. 
21- Nematipour, M. (2012). A study of Iranian EFL learners' autonomy level and its relationship with learning style. English Linguistics Research, 1(1), 126-136.

22- RINGO,L. (2014). STUDENTS'PERCEPTUAL LEARNING STYLE PREFERENCES AND ACTIVITIES FOR PRACTICING THE USE OF ENGLISH TENSES IN ESTONIAN BASIC SCHOOL.

23- Reid, J. M. (1987). The learning style preferences of ESL students. TESOL quarterly, 21 (1), 87-111.

24- Samaranayake, S. W. (2016). Oral competency of ESL/EFL learners in Sri Lankan rural school context. SAGE Open, 6 (2), 2158244016654202.

25- Shen, M. Y. (2010). Effects of perceptual learning style preferences on L2 lexical inferencing. System, 38 (4), 539-547.

26- Vincent, A.,\&Ross, D. (2001).Learning Style Awareness. Journal of Research on computing in Education, 33(5).

27- Wang. T., \& Moore, L. (2007). Exploring learning style preferences of Chinese undergraduate students in Australian transitional programs. International Journal of Pedagogies and Learning, 3 (2), 31-41. 